\title{
APLICAÇÃO FOLIAR DE CÁLCIO EM PESSEGUEIRO NA SERRA GAÚCHA: AVALIAÇÃO DO TEOR DE NUTRIENTES NA FOLHA, NO FRUTO E PRODUÇÃO'
}

\author{
GUSTAVO BRUNETTO ${ }^{2}$, GEORGE WELLINGTON DE MELO $^{3}$, JOÃO KAMINSKI $^{4}$
}

RESUMO - Na região Sul do Brasil, as aplicações foliares de cálcio têm sido usadas durante o ciclo produtivo do pessegueiro. Entretanto se carece de conhecimentos sobre o teor de cálcio e de outros nutrientes na folha, usada para estimar o estado nutricional da planta, no fruto, utilizado como referência para definir a ocorrência de distúrbio fisiológico e na produção. O trabalho objetivou avaliar o efeito de pulverizações foliares de diferentes fontes de cálcio no seu teor e de outros nutrientes nas folhas, nos frutos e na produção. O trabalho compreendeu dois experimentos e foi conduzido na safra agrícola de 2003/2004, em um pomar comercial de pessegueiro da cultivar Chimarrita, em Pinto Bandeira-RS, sobre um Cambissolo Húmico. O experimento 1 consistiu de uma, duas e três pulverizações foliares de cloreto de cálcio nas concentrações de 0 (água); 0,$5 ; 1,0$ e 2,0\%. O experimento 2 compreendeu uma, duas e três pulverizações foliares de nitrato de cálcio nas concentrações de 0 (água); 0,$5 ; 1,0$ e 2,0\%. O delineamento experimental usado nos dois experimentos foi de blocos ao acaso, com três repetições e três plantas por parcela, que foram distribuídas ao longo da linha de plantio. Nas plantas dos dois experimentos, foram coletadas folhas completas (limbo+pecíolo) do terço médio dos ramos do ano, nos diferentes lados da planta, secas, moídas e preparadas para a análise dos teores de cálcio, nitrogênio, potássio e magnésio. Na maturação completa, os frutos foram colhidos e determinados a massa, a produção e os teores de cálcio, nitrogênio, potássio e magnésio. Os resultados mostraram que as aplicações foliares de cloreto de cálcio e nitrato de cálcio durante o ciclo produtivo do pessegueiro aumentaram o teor de cálcio na folha. Porém, não afetaram o teor de nitrogênio, potássio e magnésio na folha, o teor de cálcio, nitrogênio, potássio e magnésio no fruto e na produção.

Termos de Indexação: Prunus persica, nutrição mineral, fontes de cálcio.

\section{FOLIAR APPLICATION OF CALCIUM IN PEACH IN SERRA GAÚCHA: EVALUATION OF CONTENT OF NUTRIENTS IN THE LEAF, FRUIT AND YIELD}

\begin{abstract}
Foliar application of calcium in Peach tree in the Southern Brasil is used during productive cycle, without any information about calcium content and other nutrients in the leaves, fruits and yield. Two experiments were carried out in 2003/2004 to evaluate the effect of foliar application of different sources of calcium in its content and other nutrients in the leaf, fruit and yield of peach trees, Chimarrita cultivar, at an Haplumbrept soil in Southern Brazil, Pinto Bandeira city. The treatments in the experiment 1 were three foliar applications of calcium chloride, concentrations 0 (water), $0.5,1.0$ and 2.0\%.Experiment 2 were three foliar applications of calcium nitrate, concentrations 0 (water), $0.5,1.0$ and $2.0 \%$. A randomized block experimental design was used with three replications and three plants for treatment. Leaves were collected, oven-dried and analyzed total calcium, nitrogen, potassium and magnesium. In the maturation, fruits were collected and determined the mass, yield and total content of calcium, nitrogen, potassium and magnesium. The results showed that foliar applications of calcium in the form of chloride and nitrate in peach tree, increase calcium content in the leaves, but did not affect the content of nitrogen, potassium and magnesium in the leaves, content of calcium, nitrogen, potassium and magnesium in the fruit and yield.
\end{abstract}

Index terms: Prunus persica, mineral nutrition, sources of calcium.

${ }^{1}$ (Trabalho 110-07).Recebido em: 23-04-2007. Aceito para publicação em: 19-10-2007. Trabalho realizado com recursos da Embrapa Uva e Vinho. ${ }^{2}$ Engenheiro Agrônomo, Doutor em Ciência do Solo, Professor Substituto do Departamento de Solos da Universidade Federal de Santa Maria (UFSM). Rua Erly de Almeida Lima, 546, apartamento 302, Bairro Camobi, Cep: 97105-120, Santa Maria-RS, Brasil. E-mail: brunetto.gustavo@gmail.com (autor para correspondência).

${ }^{3}$ Engenheiro Agrônomo, Doutor em Ciência do Solo, Pesquisador da Embrapa Uva e Vinho. Embrapa Uva e Vinho, Caixa Postal 130, Rua Livramento 515, Cep: 95700-000, Bento Gonçalves-RS, Brasil. E-mail: george@cnpuv.embrapa.br.

${ }^{4}$ Engenheiro Agrônomo, Doutor em Ciência do Solo, Professor colaborador do Departamento de Solos da Universidade Federal de Santa Maria. Bolsista em produtividade do CNPq. UFSM, Centro de Ciências Rurais (CCR), Dep. de Solos, Caixa Postal 221, Cep: 97105-900, Santa Maria-RS, Brasil. E-mail: jk@smail.ufsm.br.

Rev. Bras. Frutic., Jaboticabal - SP, v. 30, n. 2, p. 528-533, Junho 2008 


\section{INTRODUÇÃO}

O Rio Grande do Sul (RS) possui a maior área cultivada com pessegueiro do Brasil, e a região da Serra Gaúcha é a maior produtora de pêssego para o consumo in natura. Os pomares são formados, normalmente, por cultivares com frutos de polpa branca, como Chimarrita, e se localizam em solos com textura argilosa ou muito argilosa, alto teor de matéria orgânica, baixa fertilidade e elevada acidez. Por isso a calagem é indispensável, tanto para criar um ambiente favorável ao desenvolvimento das raízes como para incrementar a oferta de cálcio para a planta, pois a aplicação de calcário em solos com carga variável, nos quais se cultiva pessegueiros, aumenta os valores de $\mathrm{pH}$ e as cargas negativas do solo. Isso causa maior adsorção de cálcio, mas não garante acréscimos na sua atividade na solução do solo.

O pessegueiro, em geral, absorve as maiores quantidades de cálcio do solo, durante um pequeno período do ano, em taxas relativamente altas. Por isso, pode ser necessária sua suplementação, que é feita por pulverização dos frutos com sais de cálcio, para garantir melhores características destes, já que o cálcio se associa às substâncias pécticas da lamela média e as membranas celulares, preservando as características de permeabilidade da membrana celular (Poovaiah et al., 1988), o que confere maior rigidez ao tecido e, também, diminui a ocorrência de doenças e distúrbios fisiológicos em pós-colheita, como a lanosidade (Conway et al., 1994; Maganaris et al., 2005; Elmer et al., 2007), pois os novos tecidos são formados com o cálcio recém-absorvido, devido às dificuldades de sua remobilização a partir da folha.

Nos Estados do RS e Santa Catarina (SC), a Comissão de Química e Fertilidade do Solo (CQFS-RS/SC, 2004) não menciona informações sobre a necessidade de pulverização foliar de cálcio em pessegueiros. Entretanto, essa é uma prática comum durante o período produtivo das plantas e, quando realizada, é baseada em informações obtidas em tradicionais países produtores de pêssego e de recomendações técnicas de outras frutíferas. Somado a isso, alguns estudos realizados na região Sul do Brasil indicam que nem sempre a pulverização de frutos de pêssego com diferentes fontes de cálcio melhora as características físicas e químicas do fruto e aumenta seu período de armazenamento (Vizzoto et al., 2002). Entretanto, são escassos os trabalhos que avaliam o efeito da aplicação de cálcio sobre o seu teor e de outros nutrientes na folha, que é usada para estimar o estado nutricional da planta (CQFS-RS/SC, 2004), no fruto, que pode ser usado como indicativo para definir a ocorrência de distúrbio fisiológico, uma vez que a sua ocorrência está relacionada ao alto conteúdo de $\mathrm{N}, \mathrm{Mg}$ e $\mathrm{K}$, e suas relações com o cálcio, fenômeno já bem conhecido em frutos de macieira (Argenta \& Suzuki, 1994; Nachtigall \& Freire, 1998; Amarante et al., 2006a; Amarante et al., 2006b) e sobre a produção e seus indicadores, como a massa, que está associada à diluição de cálcio no fruto. Assim, torna-se necessária a realização de experimentos de campo para melhor compreender o efeito das pulverizações de fontes de cálcio, normalmente usadas em pomares de pessegueiro.

O trabalho objetivou avaliar o efeito de pulverizações foliares de diferentes fontes de cálcio no seu teor e de outros nutrientes nas folhas, nos frutos e na produção.

\section{MATERIAL E MÉTODOS}

O trabalho compreendeu dois experimentos e foi conduzido em um pomar comercial de pessegueiro (Prunus persica, L. Batsch), cultivar Chimarrita, porta-enxerto Aldrighi, no município de Pinto Bandeira, região fisiográfica da Serra Gaúcha do RS, safra agrícola de 2003/2004. Os pessegueiros foram plantados no ano de 1995, espaçamento 4,0m x 2,5m e conduzidos em taça com quatro pernas. O solo do experimento foi um Cambissolo Húmico (Embrapa, 1999) e apresentava, na camada de 0-20 cm, os seguintes atributos: argila $270 \mathrm{~g} \mathrm{~kg}^{-1}$; matéria orgânica $54 \mathrm{~g} \mathrm{~kg}^{-1} ; \mathrm{pH}$ em água 6,3; Índice SMP 5,7; Ca trocável $93,0 \mathrm{mmol}_{\mathrm{c}} \mathrm{dm}^{-3} ; \mathrm{Mg}$ trocável $41,0 \mathrm{mmol}_{\mathrm{c}} \mathrm{dm}^{-3} ;$ Al trocável $0,0 \mathrm{mmol}_{\mathrm{c}}$ $\mathrm{dm}^{-3}$; P disponível $113 \mathrm{mg} \mathrm{dm}^{-3}$ (Mehlich 1), e $\mathrm{K}$ disponível $2,62 \mathrm{mmol}_{\mathrm{c}} \mathrm{dm}^{-3}$.

O experimento 1 consistiu de uma (21-11-2001), duas (0612-2001) e três (19-12-2001) pulverizações foliares de cloreto de cálcio nas concentrações de 0 (água); 0,$5 ; 1,0$ e 2,0\%. O experimento 2 compreendeu uma (21-11-2001), duas (06-12-2001) e três (19-12-2001) pulverizações foliares de nitrato de cálcio nas concentrações de 0 (água); 0,$5 ; 1,0$ e 2,0\%. Nos dois experimentos, a vazão de aplicação das concentrações de cloreto de cálcio e nitrato de cálcio foi de $1.000 \mathrm{~L} \mathrm{ha}^{-1} \mathrm{e}$ iniciaram após a plena floração, finalizando uma semana antes da colheita dos frutos. Todas as aplicações foram realizadas no intervalo entre as oito e as dez horas da manhã. Os pessegueiros das áreas experimentais receberam a aplicação via solo de nitrogênio, fósforo e potássio, conforme a CFS-RS/SC (1994), fungicidas, inseticidas, poda de inverno, de verão e raleio manual de frutos. O delineamento experimental usado nos dois experimentos foi de blocos ao acaso, com três repetições e três plantas por parcela, que foram distribuídas ao longo da linha de plantio.

Nas plantas dos dois experimentos, foram coletadas folhas completas (limbo+pecíolo) do terço médio dos ramos do ano, nos diferentes lados da planta, secas, moídas e preparadas para a análise de cálcio, nitrogênio, potássio e magnésio, conforme metodologia proposta por Tedesco et al. (1995). Na maturação completa, todos os frutos das plantas de cada tratamento foram colhidos, determinado a massa de 20 frutos, usando balança digital e a produção por planta. Posteriormente, em uma parte dos frutos, foram cortadas duas frações longitudinais triangulares em cada fruto, cortadas de forma radial, incluindo a epiderme. Em seguida, as frações foram trituradas e digeridas a $350^{\circ} \mathrm{C}$, usandose uma mistura de ácido sulfúrico concentrado e água oxigenada 30 volumes, e os teores de cálcio, nitrogênio, potássio e magnésio, determinados segundo Tedesco et al. (1995).

Os resultados obtidos foram submetidos à análise de variância e, quando os efeitos foram significativos, foram ajustadas equações de regressão, testando-se os modelos linear, quadrático e cúbico, pelo teste $\mathrm{F}$, escolhendo-se aquele com significância maior que $95 \%$. 


\section{RESULTADOS E DISCUSSÃO}

As pulverizações com cloreto de cálcio, nas concentrações utilizadas, aumentaram linearmente os teores de cálcio nas folhas (Tabela 1), mas eles tenderam a ficar menores que as concentrações adotadas para a faixa de interpretação considerada normal pela CQFS RS-SC (2004), que se situam entre 16,4 e $26,1 \mathrm{~g} \mathrm{~kg}^{-1}$. Porém, convém relatar que os valores encontrados estão ou próximos ao limite mínimo da faixa normal, $14,9 \mathrm{~g} \mathrm{~kg}^{-1}$, ou se inserem nela, $17,4 \mathrm{~g} \mathrm{~kg}^{-1}$. Entretanto, a adoção de valores rígidos para avaliar o estado nutricional ou definir níveis críticos de cálcio na folha pode não refletir esta condição no fruto, dada a unidirecionalidade de absorção deste nutriente na planta e sua pequena remobilização, uma vez que o cálcio está associado às substâncias pécticas da lamela média e com as membranas celulares. Isto também foi relatado por Crisosto et al. (1995; 1997 e 2000) em pêssego. Não foram observadas alterações significativas nas concentrações de nitrogênio, de potássio e de magnésio nas folhas e nos frutos (Tabela 1), como encontrado por Ribeiro et al. (2003) em macieira. Também a massa dos frutos e a produção das plantas não foram alteradas com as pulverizações com cloreto de cálcio (Tabela 2), e isso mostra a sua pouca importância no incremento destas variáveis.

Quando se utilizou nitrato de cálcio nas pulverizações, o comportamento foi muito similar ao cloreto de cálcio no que se refere às suas concentrações tanto nas folhas como nos frutos
(Tabela 3), aumentos lineares nas concentrações nas folhas e do mesmo modo que o cloreto de cálcio, ou muito próximas, ou inserindo-se no início da faixa normal $\left(16,4\right.$ a $\left.26,1 \mathrm{~g} \mathrm{~kg}^{-1}\right)$. Já as concentrações de nitrogênio nas folhas aumentaram linearmente com mais de uma aplicação, mas não houve diferença significativa dos teores deste nutriente nos frutos (Tabela 3). O teor de nitrogênio nas folhas, em todas as concentrações e aplicações, também ficou na faixa abaixo do normal $\left(18,9\right.$ a $\left.32,5 \mathrm{~g} \mathrm{~kg}^{-1}\right)$, normal para potássio (13,1 a 20,6 $\left.\mathrm{g} \mathrm{kg}^{-1}\right)$ e abaixo do normal ( 1,9 a $5,1 \mathrm{~g} \mathrm{~kg}$ $\left.{ }^{1}\right)$ ou normal $\left(5,2\right.$ a $\left.8,3 \mathrm{~g} \mathrm{~kg}^{-1}\right)$ para magnésio, similar ao observado com a aplicação de cloreto de cálcio. A massa dos frutos e a produção das plantas não foram afetadas com as pulverizações com nitrato de cálcio (Tabela 4), como verificado com o uso de cloreto de cálcio (Tabela 2).

$\mathrm{O}$ uso de pulverizações foliares de fontes de cálcio em frutíferas, entre as quais o pessegueiro, em geral, aumenta o seu teor nas folhas. Porém, não se detecta seu aumento no fruto, pois a sua absorção fica limitada ao tecido onde é depositado e apresenta pequena remobilização (Crisosto et al., 2000). A baixa resposta à aplicação foliar de cálcio em pessegueiro, neste trabalho, pode estar associada aos teores de cálcio no solo, que foram de $93,0 \mathrm{mmol}_{\mathrm{c}} \mathrm{dm}^{-3}$, que é considerado alto (acima de 40,0 $\mathrm{mmol}_{\mathrm{c}} \mathrm{kg}^{-1}$ ) pela CQFS-RS/SC (2004). Estes resultados concordam com os obtidos por Vizzoto et al. (2002), que também não encontraram efeito de pulverizações foliares de sais de cálcio em pessegueiro cultivado na Serra Gaúcha do RS.

TABELA 1 - Teores de cálcio, nitrogênio, potássio e magnésio nas folhas e nos frutos de pêssego submetidos à aplicação de cloreto de cálcio

\begin{tabular}{|c|c|c|c|c|c|c|c|c|}
\hline \multirow{2}{*}{ Concentração } & \multicolumn{4}{|c|}{ Folha } & \multicolumn{4}{|c|}{ Fruto } \\
\hline & Nitrogênio & Potássio & Cálcio & Magnésio & Nitrogênio & Potássio & Cálcio & Magnésio \\
\hline \multirow[t]{2}{*}{$\%$} & \multicolumn{4}{|c|}{$\mathrm{g} \mathrm{kg}^{-1}$} & \multicolumn{4}{|c|}{$\mathrm{mg} \mathrm{kg}^{-1}$} \\
\hline & \multicolumn{8}{|c|}{1 aplicação } \\
\hline 0 & $24,05^{\mathrm{ns}}$ & $14,62^{\mathrm{ns}}$ & $15,78^{1}$ & $5,69^{\mathrm{ns}}$ & $481^{\mathrm{ns}}$ & $1805^{\mathrm{ns}}$ & $41,64^{\mathrm{ns}}$ & $83^{\mathrm{ns}}$ \\
\hline 0,5 & 22,09 & 14,41 & 15,75 & 5,41 & 547 & 1806 & 41,14 & 84 \\
\hline 1,0 & 24,10 & 15,89 & 16,35 & 4,88 & 545 & 1825 & 42,29 & 87 \\
\hline 2,0 & 23,62 & 16,00 & 16,75 & 5,01 & 525 & 1805 & 41,64 & 86 \\
\hline \multirow[t]{2}{*}{$\mathrm{CV}, \%$} & 5,07 & 9,61 & 1,40 & 10,96 & 8,61 & 3,34 & 1,75 & 3,37 \\
\hline & \multicolumn{8}{|c|}{2 aplicações } \\
\hline 0 & $23,50^{\mathrm{ns}}$ & $15,90^{\mathrm{ns}}$ & $16,32^{2}$ & $6,30^{\mathrm{ns}}$ & $520^{\text {ns }}$ & $1820^{\mathrm{ns}}$ & $41,14^{\mathrm{ns}}$ & $78^{\mathrm{ns}}$ \\
\hline 0,5 & 23,74 & 17,61 & 16,09 & 5,20 & 547 & 1858 & 38,76 & 79 \\
\hline 1,0 & 23,20 & 16,39 & 17,10 & 5,60 & 613 & 1885 & 38,76 & 82 \\
\hline 2,0 & 23,40 & 17,47 & 17,46 & 5,91 & 612 & 1889 & 42,29 & 83 \\
\hline \multirow[t]{2}{*}{$\mathrm{CV}, \%$} & 2,50 & 5,61 & 3,36 & 11,56 & 7,39 & 2,21 & 10,82 & 2,48 \\
\hline & \multicolumn{8}{|c|}{3 aplicações } \\
\hline 0 & $24,15^{\mathrm{ns}}$ & $14,00^{\mathrm{ns}}$ & $15,21^{3}$ & $6,20^{\mathrm{ns}}$ & $515^{\text {ns }}$ & $1738^{\mathrm{ns}}$ & $39,64^{\mathrm{ns}}$ & $79^{\text {ns }}$ \\
\hline 0,5 & 23,90 & 17,47 & 14,98 & 4,79 & 591 & 1752 & 35,24 & 84 \\
\hline 1,0 & 24,72 & 17,47 & 16,10 & 4,66 & 535 & 1778 & 38,76 & 76 \\
\hline 2,0 & 24,06 & 16,93 & 16,44 & 5,97 & 569 & 1740 & 41,31 & 85 \\
\hline $\mathrm{CV}, \%$ & 2,85 & 13,15 & 4,83 & 15,00 & 7,79 & 4,09 & 10,80 & 2,91 \\
\hline
\end{tabular}

ns $=$ não-significativo ao nível de $5 \%$ de erro; ${ }^{(1)} \hat{y}=15,28+0,351 x\left(R^{2}=0,88^{*}\right) ;(2) \hat{y}=15,63+0,443 x\left(R^{2}=0,78^{*}\right) ;{ }^{(3)} \hat{y}=14,48+0,481 x\left(R^{2}=0,79^{*}\right)$. 
TABELA 2 - Massa dos frutos e produção em pessegueiros submetidos à aplicação de cloreto de cálcio

\begin{tabular}{|c|c|c|}
\hline Concentração & Massa do fruto & Produção por planta \\
\hline \multirow[t]{2}{*}{$\%$} & $\mathrm{~g}$ & $\mathrm{~kg}_{\text {planta }}{ }^{-1}$ \\
\hline & & \\
\hline 0 & $97,70^{\text {ns }}$ & $48,85^{\text {ns }}$ \\
\hline 0,5 & 96,57 & 48,27 \\
\hline 1,0 & 95,00 & 47,50 \\
\hline 2,0 & 99,00 & 49,52 \\
\hline \multirow[t]{2}{*}{$\mathrm{CV}, \%$} & 2,39 & 2,30 \\
\hline & & \\
\hline 0 & $100,60^{\mathrm{ns}}$ & $50,30^{\text {ns }}$ \\
\hline 0,5 & 104,37 & 52,18 \\
\hline 1,0 & 104,40 & 52,20 \\
\hline 2,0 & 100,50 & 50,25 \\
\hline \multirow[t]{2}{*}{$\mathrm{CV}, \%$} & 2,09 & 2,50 \\
\hline & & \\
\hline 0 & $97,70^{\text {ns }}$ & $48,85^{\text {ns }}$ \\
\hline 0,5 & 97,20 & 48,60 \\
\hline 1,0 & 98,00 & 49,00 \\
\hline 2,0 & 97,50 & 48,75 \\
\hline $\mathrm{CV}, \%$ & 1,25 & 2,00 \\
\hline
\end{tabular}

ns $=$ não-significativo ao nível de $5 \%$ de erro.

TABELA 3 - Teores de cálcio, nitrogênio, potássio e magnésio nas folhas e nos frutos de pêssego submetidos à aplicação de nitrato de cálcio

\begin{tabular}{|c|c|c|c|c|c|c|c|c|}
\hline \multirow{2}{*}{ Concentração } & \multicolumn{4}{|c|}{ Folha } & \multicolumn{4}{|c|}{ Fruto } \\
\hline & Nitrogênio & Potássio & Cálcio & Magnésio & Nitrogênio & Potássio & Cálcio & Magnésio \\
\hline \multirow[t]{2}{*}{$\%$} & \multicolumn{4}{|c|}{$\mathrm{g} \mathrm{kg}^{-1}$} & \multicolumn{4}{|c|}{$\mathrm{mg} \mathrm{kg}^{-1}$} \\
\hline & \multicolumn{8}{|c|}{1 aplicação } \\
\hline 0 & $22,50^{\mathrm{ns}}$ & $15,05^{\text {ns }}$ & $16,15^{3}$ & $5,55^{\mathrm{ns}}$ & $520^{\mathrm{ns}}$ & $1650^{\mathrm{ns}}$ & $40,14^{\text {ns }}$ & $75^{\mathrm{ns}}$ \\
\hline 0,5 & 22,31 & 17,47 & 16,25 & 5,39 & 510 & 1646 & 41,15 & 74 \\
\hline 1,0 & 22,53 & 16,79 & 16,55 & 5,36 & 517 & 1805 & 39,00 & 77 \\
\hline 2,0 & 22,55 & 17,20 & 16,84 & 5,35 & 522 & 1725 & 41,15 & 76 \\
\hline \multirow[t]{2}{*}{$\mathrm{CV}, \%$} & 3,17 & 12,21 & 1,71 & 2,01 & 2,26 & 6,98 & 4,15 & 6,89 \\
\hline & \multicolumn{8}{|c|}{2 aplicações } \\
\hline 0 & $23,15^{1}$ & $15,75^{\mathrm{ns}}$ & $15,80^{4}$ & $4,90^{\mathrm{ns}}$ & $510^{\mathrm{ns}}$ & $1830^{\text {ns }}$ & $39,50^{\text {ns }}$ & $79^{\mathrm{ns}}$ \\
\hline 0,5 & 24,25 & 16,03 & 15,33 & 4,94 & 512 & 1858 & 40,64 & 84 \\
\hline 1,0 & 24,35 & 15,25 & 16,22 & 4,96 & 522 & 1859 & 40,14 & 81 \\
\hline 2,0 & 24,28 & 15,57 & 16,50 & 5,01 & 522 & 1725 & 40,15 & 79 \\
\hline \multirow[t]{2}{*}{$\mathrm{CV}, \%$} & 1,50 & 1,21 & 1,27 & 1,91 & 2,00 & 5,88 & 4,34 & 5,47 \\
\hline & \multicolumn{8}{|c|}{3 aplicações } \\
\hline 0 & $23,85^{2}$ & $16,55^{\mathrm{ns}}$ & $15,90^{5}$ & $4,88^{\mathrm{ns}}$ & $520^{\mathrm{ns}}$ & $1713^{\mathrm{ns}}$ & $42,29^{\text {ns }}$ & $77^{\mathrm{ns}}$ \\
\hline 0,5 & 23,63 & 19,90 & 16,22 & 4,77 & 520 & 1776 & 42,14 & 83 \\
\hline 1,0 & 24,72 & 17,47 & 16,81 & 4,96 & 522 & 1772 & 42,28 & 77 \\
\hline 2,0 & 26,25 & 19,63 & 17,25 & 4,83 & 524 & 1802 & 42,29 & 74 \\
\hline $\mathrm{CV}, \%$ & 2,70 & 10,73 & 4,62 & 3,08 & 2,20 & 3,08 & 1,36 & 7,63 \\
\hline
\end{tabular}

ns = não-significativo ao nível de $5 \%$ de erro; ${ }^{(1)} \hat{y}=23,13+0,349 x\left(R^{2}=0,62^{*}\right) ;{ }^{(2)} \hat{y}=22,54+0,829 x\left(R^{2}=0,81^{*}\right) ;{ }^{(3)} \hat{y}=15,85+0,237 x\left(R^{2}=0,96^{*}\right)$; (4) $\hat{y}=15,21+0,299 x\left(R^{2}=0,57^{*}\right) ;{ }^{(5)} \hat{y}=15,38+0,464 x\left(R^{2}=0,98^{*}\right)$. 
TABELA 4 - Massa dos frutos e produção em pessegueiros submetidos à aplicação de nitrato de cálcio.

\begin{tabular}{|c|c|c|}
\hline Concentração & Massa do fruto & Produção por planta \\
\hline \multirow[t]{2}{*}{$\%$} & $\mathrm{~g}$ & $\mathrm{~kg}$ planta $^{-1}$ \\
\hline & & \\
\hline 0 & $97,70^{\mathrm{ns}}$ & $48,85^{\text {ns }}$ \\
\hline 0,5 & 98,50 & 49,25 \\
\hline 1,0 & 96,17 & 48,08 \\
\hline 2,0 & 96,40 & 48,70 \\
\hline \multirow[t]{2}{*}{$\mathrm{CV}, \%$} & 2,00 & 2,70 \\
\hline & & \\
\hline 0 & $98,70^{\mathrm{ns}}$ & $49,35^{\text {ns }}$ \\
\hline 0,5 & 98,50 & 49,20 \\
\hline 1,0 & 99,50 & 49,60 \\
\hline 2,0 & 99,50 & 49,75 \\
\hline \multirow[t]{2}{*}{$\mathrm{CV}, \%$} & 2,00 & 2,50 \\
\hline & & \\
\hline 0 & $99,20^{\mathrm{ns}}$ & $49,60^{\mathrm{ns}}$ \\
\hline 0,5 & 99,87 & 49,93 \\
\hline 1,0 & 98,50 & 49,25 \\
\hline 2,0 & 99,99 & 50,00 \\
\hline $\mathrm{CV}, \%$ & 1,60 & 2,60 \\
\hline
\end{tabular}

ns = não-significativo ao nível de 5\% de erro.

\section{CONCLUSÃO}

As aplicações foliares de cloreto de cálcio e nitrato de cálcio durante o ciclo produtivo do pessegueiro aumentaram o teor de cálcio na folha. Porém, não afetaram o teor de nitrogênio, potássio e magnésio na folha, o teor de cálcio, nitrogênio, potássio e magnésio no fruto, e a produção.

\section{AGRADECIMENTOS}

Aos laboratoristas, Volmir Scanagatta e Alexandre Mussnich (Laboratório de Análise de Solo e Tecido da Embrapa Uva e Vinho), pelo auxílio na execução dos experimentos e análises laboratoriais.

\section{REFERÊNCIAS}

AMARANTE, C.V.T.; CHAVES, D.V.; ERNANI, P.R.E. Análise multivariada de atributos nutricionais associados ao "bitter pit” em maçãs 'Gala'. Pesquisa Agropecuária Brasileira, Brasília, v.41, p.841-846, 2006a.

AMARANTE, C.V.T.; CHAVES, D.V.; ERNANI, P.R.E. Composição mineral e severidade de "bitter pit" em maçãs 'Catarina'. Revista Brasileira de Fruticultura, Jaboticabal, v. 28, p. 51-54, 2006b.
ARGENTA, L.C.; SUZUKI, A. Relação entre teores minerais e freqüência de bitter pit em maçã cv. Gala no Brasil. Revista Brasileira de Fruticultura, Jaboticabal, v.16, p.267-277, 1994.

COMISSÃO DE FERTILIDADE DO SOLO - RS/SC. Recomendações de adubação e calagem para os Estados do Rio Grande do Sul e Santa Catarina. 3.ed. Passo Fundo: SBPC Núcleo Regional Sul/EMBRAPA/CNPT, 1994. 224 p.

COMISSÃO DE QUIIMICA E FERTILIDADE DO SOLO. Manual de adubação e calagem para os Estados do Rio Grande do Sul e de Santa Catarina. 10. ed. Porto Alegre: SBCS - Núcleo Regional Sul/UFRGS, 2004. 400 p.

CONWAY, W.S.; SANS, C.E.; WANG, C.Y.; ABBOTT, J.A. Additive effects of postharvest calcium and heat treatment on reducing decay maintaining quality in apples. Journal of the American Society for Horticultural Science, Alexandria, v.119, n.1, p.4953, 1994.

CRISOSTO, C.H.; MITCHELL, F.G.; JOHNSON, S. Factors in fresh market stone fruit quality. Postharvest News and Information, Wallington, v. 6, p. 17-21, 1995.

CRISOSTO, C.H.; JOHNSON, R.S.; DEJONG, T.; DAY, K.R. Orchard factors affecting postharvest stone fruit quality. HorScience, Alexandria, v.32, p.820-823, 1997.

CRISOSTO, C.H.; DAY, K.R.; JOHNSON, R.S.; GARNER, D. Influence of in-season foliar calcium sprays on fruit quality and surface discoloration incidence of Peaches and nectarines. Journal of American Pomological Society, v.54, p. 118-122, 2000.

ELMER, P.A.G.; SPEERS, T.M.; WOOD, P.N. Effects of pre-harvest foliar calcium sprays on fruit calcium levels and brown rot of peaches. Crop Protection, Kidlington, v.26, p.11-18, 2007.

EMPRESA BRASILEIRA DE PESQUISA AGROPECUÁRIACNPS. Sistema brasileiro de classificação de solos. Brasília: EMBRAPA, 1999.412 p.

MANGANARIS, G.A.; VASILAKAKIS, M.; MIGNANI, I.; DIAMANTIDIS, G.; TZAVELLA-KLONARI, K. The effect of preharvest calcium sprays on quality attributes, physicochemical aspects of cell wall components and susceptibility to brown rot of peach fruits (Prunus persica L. cv. Andross). Scientia Horticulturae, Amsterdam, v.107, p.43-50, 2005.

NACHTIGALL, G.R.; FREIRE, C.J.S. Previsão da incidência de "bitter pit" em maçãs através dos teores de cálcio em folhas e frutos. Revista Brasileira de Fruticultura, Jaboticabal, v.20, p.158-166, 1998.

POOVAIAH, B.W. Molecular and cellular aspects of calcium action in plants. HortScience, Alexandria, v.23, p.267-271, 1988. 
RIBEIRO, D.C.; ERNANI, P.R.; AMARANTE, C.V.T.; DIAS, J.; BESSEGATO, A. Nem sempre é necessário pulverizar os frutos de macieira em pré-colheita com cálcio. In: CONGRESSO BRASILEIRO DE CIÊNCIA DO SOLO, 24., 2003, Ribeirão Preto, SP. Anais... v.1, p.47-48.

TEDESCO, M.J.; GIANELLO, C.; BISSANI, C.A.; BOHNEN, H.; VOLKWEISS, S.J. Análise do solo, planta e outros materiais. 2.ed. Porto Alegre: UFRGS, 1995. 174p. (Boletim técnico, 5).
VIZZOTTO, M.; ANTUNES, P.L.; DALBOSCO, V.Aplicação de cálcio em pré-colheita na conservação de pêssego [Prunus persica (L.) Batsch], cv. chiripá. Revista Brasileira de Agrociência, Pelotas, v.8, p.31-35, 2002. 